\title{
Sosialisasi Dan Penyuluhan Hukum Tentang Hibah, Wasiat, Wakaf, Dan Waris Di Wilayah Kecamatan Cinere Kota Depok
}

\author{
Ahmad Baihaki ${ }^{1}$, Yulianto Syahyu ${ }^{1}$, Adi Nur Rohman ${ }^{1, *}$, Harinanto Sugiono ${ }^{1}$ \\ ${ }^{1}$ Fakultas Hukum, Universitas Bhayangkara Jakarta Raya; Jl. Raya Perjuangan, Marga \\ Mulya, Bekasi Utara, Jawa Barat 17121. Telp: 021-88955882, 889955883, e-mail: \\ baihaki.vision@gmail.com; e-mail:ysa_law@yahoo.com,e-mail: adi.nur@dsn.ubharajaya.ac.id \\ e-mail: notaris.ppat.harinanto.sugiono@gmail.com \\ * Korespondensi: e-mail: adi.nur@dsn.ubharajaya.ac.id
}

\begin{abstract}
Grants, wills, endowments, and inheritance are legal instruments that are often used by someone to transfer their assets or wealth to others. But in practice, these four things become legal issues in society, especially for Muslim residents. Legal settlement of. This case was settled by the Religious Court. Based on case data that entered the Depok City Religious Court for the past five years until 2019, there were 24 grant cases approved, 20 wills, 8 endorsed cases, and $48 \mathrm{~s}$ allocation for inheritance. Some of the things behind this case and the most crucial is due to the ignorance of the community against the provisions of Indonesian law regarding grants, wills, endowments, and inheritance. On that basis, a Lecturer in the Faculty of Law of the University of Bhayangkara, Greater Jakarta, conducted socialization and legal counseling on grants, wills, endowments, and inheritance on Compilation of Islamic Law for the people in the Cinere District area. The will, endowments, and inheritance in the Compilation of Islamic Law is still very minimal. After the socialization and discussion of the law, the community's knowledge and awareness will require the implementation and legalization of grants, wills, endowments, and inheritance to improve legal problems up to the increasingly increasing religious court. The output resulting from this activity is planned to be made a waqf pocketbook as an additional reference about the legal grants, wills, endowments, and inheritance according to the Compilation of Islamic Law. Besides, the results of the activities are published in the form of implementation reports and published in scientific journals to provide comprehensive and academic-wide benefits and practical levels.
\end{abstract}

Keywords: Grants, wills, endowments, inheritance

\begin{abstract}
Abstrak
Hibah, wasiat, wakaf, dan waris merupakan salah satu instrumen hukum yang sering digunakan oleh seseorang untuk mengalihkan harta atau kekayaannya kepada orang lain. Namun dalam praktiknya, keempat hal tersebut seringkali menjadi kasus hukum di masyarakat, khususnya bagi penduduk Muslim. Penyelesaian hukum atas keempat perkara tersebut diselesaikan Pengadilan Agama. Berdasarkan data perkara yang masuk ke Pengadilan Agama Kota Depok selama lima tahun terakhir sampai dengan tahun 2019 tercatat 24 kasus hibah, 20 perkara wasiat, 8 perkara sengketa wakaf, dan 48 sengketa pembagian waris. Beberapa hal melatarbelakangi kasus tersebut dan yang paling krusial adalah karena ketidaktahuan masyarakat terhadap ketentuan hukum positif Indonesia mengenai hibah, wasiat, wakaf, dan waris. Atas dasar itu, Dosen Fakultas Hukum Universitas Bhayangkara Jakarta Raya melakukan sosialisasi dan penyuluhan hukum tentang hibah, wasiat, wakaf, dan waris tentang Kompilasi Hukum Islam kepada masyarakat di wilayah Kecamatan Cinere. Hasil kegiatan menunjukkan bahwa pengetahuan peserta mengenai ketentuan hibah, wasiat, wakaf, dan waris dalam Kompilasi Hukum Islam masih sangat minim. Setelah adanya sosialisasi dan penyuluhan hukum tersebut pengetahuan dan kesadaran masyarakat akan pentingnya implementasi dan
\end{abstract}

Submitted: 4 Nopember 2019; Revised: 18 Nopember 2019; Accepted: 2 Desember 2019;

Published: 20 Januari 2020 
legalisasi hibah, wasiat, wakaf, dan waris dalam rangka untuk mengurangi munculnya kasus hukum sampai ke Pengadilan Agama semakin meningkat. Luaran yang dihasilkan dari kegiatan ini rencananya akan dibuat buku saku wakaf sebagai tambahan referensi tentang hukum hibah, wasiat, wakaf, dan waris menurut Kompilasi Hukum Islam. Di samping itu, hasil kegiatan didokumentasikan dalam bentuk laporan pelaksanaan dan dimuat dalam jurnal ilmiah agar bisa memberikan manfaat seluas-luasnya secara akademis dan tataran praktis.

Kata Kunci: Hibah, Wasiat, Wakaf, Waris

\section{Pendahuluan}

Konsep hukum hibah, wasiat, wakaf, dan waris merupakan praktik hukum yang sering terjadi dalam kehidupan masyarakat. Keempat konsep hukum tersebut merupakan salah satu instrumen hukum yang sering digunakan oleh seseorang untuk mengalihkan harta atau kekayaannya kepada orang lain. Namun dalam praktiknya, pelaksanaan hibah, wasiat, wakaf, dan waris seringkali digunakan secara campur aduk dan dipersamakan kedudukannya. Padahal keempat konsep hukum tersebut memiliki persamaan sekaligus perbedaan yang mendasar dalam ketentuan hukum, khususnya di Kompilasi Hukum Islam.

Keempat konsep hukum tersebut merupakan bagian hukum perdata Islam yang diatur dalam Kompilasi Hukum Islam. Konsep hukum hibah diartikan sebagai pemberian sesuatu benda melalui transaksi ('aqad) tanpa mengharapkan imbalan yang telah diketahui dengan jelas ketika pemberi masih hidup. Dalam rumusan $\mathrm{KHI}$, hibah adalah pemberian suatu benda secara sukarela dan tanpa imbalan dari seseorang kepada orang lain yang masih hidup untuk dimiliki (Pasal 171 huruf $(\mathrm{g}) \mathrm{KHI}$ ). Sedangkan wasiat adalah pemberian suatu benda dari pewaris kepada orang lain atau lembaga yang akan berlaku setelah pewaris meninggal dunia (Pasal 171 huruf (f) KHI). Sementara waris merupakan pemindahan hak pemilikan harta peninggalan (tirkah) pewaris, menentukan siapa-siapa yang berhak menjadi ahli waris dan berapa bagiannya masing-masing (Pasal 171 huruf (a) KHI). Selanjutnya wakaf dimaknai sebagai perbuatan hukum seseorang atau kelompok orang atau badan hukum yang memisahkan sebagian dari benda miliknya dan melembagakannya untuk selama-lamanya guna kepentingan ibadat atau keperluan umum lainnya sesuai dengan ajaran Islam (Pasal 215 angka (1) $\mathrm{KHI}$ ).

Konsep hukum hibah, wasiat, wakaf, dan waris memiliki persamaan dan perbedaan dalam ketentuan hukum, diantaranya terdapat persamaan dan perbedaan, yaitu dari segi pembuat, waktu pelaksanaan, dan jumlahnya. Baik hibah maupun wasiat sama-sama merupakan perjanjian sepihak dari pembuat hibah dan wasiat yang menginginkan pemindahan hak miliknya kepada orang lain pada saat mereka masih hidup. Sementara wakaf merupakan perjanjian sepihak tetapi harus melibatkan persetujuan seseorang sebagai pengelola (nadzhir). Sedangkan dalam hukum waris sama sekali tidak terkait dengan kehendak pewaris melainkan ketentuannya sudah digariskan dalam Hukum Islam yang bersifat keharusan (ijbari).

Berkaitan dengan waktu pelaksanaan, pemindahan hak milik melalui hibah dan wakaf sudah dapat dilaksanakannya pada saat pemberi hibah melaksanakannya yang keberlakuan 
hibah tanpa harus menunggu pemberi hibah meninggal. Sedangkan wasiat pelaksanaannya harus menunggu pewasiat meninggal lebih dulu baru bisa berlaku secara hukum, begitupun dalam masalah hukum waris. Sedangkan dari segi jumlahnya, baik hibah maupun wasiat samasama dibatasi paling banyak 1/3 dari harta pembuatnya (Pasal $195 \mathrm{KHI} \& 210 \mathrm{KHI}$ ). Sementara dalam hukum waris, bagian atau jumlah harta yang dapat diterima sudah ditentukan oleh ketentuan hukum Islam tanpa campur tangan atau kehendak dari pewaris.

Pelaksanaan hibah, wasiat, wakaf, dan pembagian waris seringkali menjadi persoalan hukum di masyarakat karena pelaksanaannya dilakukan tanpa didasari pengetahuan yang benar sesuai dengan ketentuan hukum Islam atau KHI. Masalah hukum krusial yang seringkali muncul ketika pemberian hibah yang dilakukan orang tua kepada salah satu anaknya tidak lagi dikaitkan dengan masalah waris atau pemberian hibah yang melampaui batas maksimal jumlah hibah yang dapat diberikan. Pelaksanaan wasiat juga terkadang berlawanan dengan normatif hukum Islam yang keberlakuannya baru bisa dilaksanakan setelah pewasiat meninggal tetapi sudah diberlakukan dan bahkan diperjualkan oleh penerima wasiat pada saat pewasiat masih hidup. Persoalan lainnya yang juga cukup krusial adalah masalah pelaksanaan wakaf benda yang tidak dilakukan secara hukum dan tidak didaftarkan oleh Pegawai Pencatat Akta Ikrar Wakaf (PPAIW). Akibatnya pemberian benda wakaf yang telah dilaksanakan oleh orang yang mewakafkan (wakif) kemudian oleh ahli waris dijualberikan kepada orang lain sehingga tujuan wakaf benda tidak lagi sesuai lagi dengan tujuan wakif sebelumnya.

Sementara dalam persoalan hukum waris juga sering terjadi pembagian harta warisan yang dilaksanakan pada saat pewaris masih hidup dengan pembagian harta warisan yang tidak sesuai dengan hukum Islam dan KHI. Akibatnya sering terjadi perselisihan yang berujung penyelesaian perkara di Pengadilan Agama. Hal ini terlihat dari statistik Perkara yang masuk ke Pengadilan Agama Kota Depok menunjukkan bahwa sejak Januari sampai dengan Juni 2019 saja jumlah sengketa perkara hibah (6 perkara), wasiat (4 perkara), wakaf (4 perkara), dan waris (14 perkara) merupakan permasalahan yang banyak terjadi setelah masalah perceraian (962 perkara).

Penyelesaian sengketa perkara hibah, wasiat, wakaf, dan waris merupakan bagian dari beberapa kewenangan absolut Pengadilan Agama berdasarkan Pasal 49 Undang-undang Nomor 7 Tahun 1989 tentang Peradilan Agama sebagaimana diubah dengan Undang-undang Nomor 3 Tahun 2006 dan Undang-undang Nomor 50 Tahun 2009. Salah satu sumber hukum yang mengatur masalah hibah, wasiat, wakaf, dan waris dalam konstruksi Hukum Islam adalah Kompilasi Hukum Islam (KHI) yang legalitas keberlakuannya didasarkan pada Instruksi Presiden Nomor 1 Tahun 1991 tentang Kompilasi Hukum Islam. KHI dijadikan sebagai salah satu sumber hukum materiil dalam penyelesaian perkara hibah, wasiat, wakaf, dan waris di lingkungan Pengadilan Agama.

Kompilasi Hukum Islam memiliki ketentuan tersendiri tentang hibah, wasiat, dan waris yang dapat dijadikan dasar hukum pelaksanaan. Oleh karena itu, penting bagi kami untuk mensosialisasikan $\mathrm{KHI}$, terutama kaitannya dengan pengaturan masalah hibah, wasiat, wakaf, 
dan waris di lingkungan masyarakat yang berada di wilayah Kecamatan Cinere Kota Depok. Kondisi sosial masyarakat yang pluralistik tetapi juga sangat agamis yang mana banyak berdiri tempat-tempat ibadah, baik masjid, musholla, maupun majlis-majlis taklim serta lembagalembaga sekolah Islam atau Madrasah. Kegiatan sosialisasi ini diharapkan bermanfaat bagi masyarakat, khususnya kalangan warga masyarakat yang berada di wilayah Kecamatan Cinere Kota Depok agar memahami, mendalami, dan menjalankan aturan hukum Islam, khususnya terkait dengan masalah hibah, wasiat, wakaf, dan waris. Pemahaman dan implementasi terhadap ketentuan masalah-masalah hukum tersebut diharapkan pula dapat mencegah munculnya masalah-masalah hukum yang berujung pada sengketa di Pengadilan Agama.

Letak Kecamatan Cinere sangat strategis karena berbatasan langsung dengan DKI Jakarta, yaitu Jakarta Selatan sehingga menjadikan Kecamatan Cinere sebagai salah satu daerah sebagai penyangga ibu kota DKI Jakarta yang menjadi jembatan utama menuju ekonomi.

Sementara jumlah Penduduk yang ada di Kecamatan Cinere selalu berubah-ubah setiap bulannya, hal ini dipengaruhi oleh beberapa faktor yaitu adanya Kelahiran, Kematian dan Perpindahan Penduduk. Berdasarkan data statistik jumlah penduduk Kecamatan Cinere tahun 2018 sebagai berikut:

Tabel 1. Jumlah Penduduk Kecamtan Cinere

\begin{tabular}{lll}
\hline No & Kelurahan & Jumlah Penduduk (Jiwa) \\
\hline 1 & Cinere & 20.469 \\
\hline 2 & Gandul & 16.622 \\
\hline 3 & Pangkalan Jati & 11.507 \\
\hline 4 & Pangkalan Jati Baru & 6.487 \\
\hline & TOTAL & 55.083
\end{tabular}

Sumber: HasI Penelitian (2020)

Sementara jumlah masjid di wilayah Kecamatan Cinere yang terdaftar resmi di Sistem Informasi Masjid (SIMAS) Direktoral Urusan Agama Islam dan Pembinaan Syariah Direktorat Jenderal Bimas Islam Kementerian Agama Republik Indonesia berjumlah 29. Tetapi berdasarkan data di lapangan dari surat undangan pelaksanaan sososialisasi dan penyuluhan berjumlah 36 Masjid.

Berdasarkan latar belakang masalah di atas maka dapat diidentifikasi beberapa masalah sebagai berikut: 1). Kurangnya pemahaman dan kesadaran masyarakat tentang pengaturan atau praktik pembagian hibah, wasiat, wakaf, dan waris berdasarkan Hukum Islam dan Kompilasi Hukum Islam. 2). Kurangnya sosialisasi aturan hukum yang mengatur tentang pengaturan atau praktik pembagian hibah, wasiat, wakaf, dan waris berdasarkan Hukum Islam dan Kompilasi Hukum Islam sebagai upaya preventif terjadinya berbagai persoalan hukum tersebut sampai ke sidang pengadilan. 


\section{Metode Pelaksanaan}

\section{A. Waktu dan Tempat Kegiatan}

Kegiatan pengabdian kepada masyarakat dilaksanakan di Kecamatan Cinere pada hari Kamis, 14 November 2019 bertempat di Aula Kantor Kecamatan Cinere. Kegiatan tersebut dilaksanakan dalam bentuk sosialisasi dan penyuluhan hukum mengenai hukum hibah, wasiat, wakaf, dan waris menurut Kompilasi Hukum Islam. Kegiatan ini dilaksanakan dalam bentuk penyuluhan hukum dan dilanjutkan dengan diskusi dan tanya jawab interaktif dengan masyarakat tentang hukum hibah, wasiat, wakaf, dan waris menurut Kompilasi Hukum Islam.

\section{B. Metode Pelaksanaan}

Adapun kegiatan pengabdian kepada masyarakat ini dilaksanakan dalam beberapa tahapan sebagai berikut: 1). Tahap persiapan meliputi: a). Penelusuran tempat pelaksanaan pengabdian kepada masyarakat di Kecamatan Cinere. b). Mengkaji lingkungan sosialkeagamaan di lingkungan Kecamatan Cinere. c). Permohonan ijin pelaksanaan ke Camat Kecamatan Cinere. d). Pembuatan proposal, ujian proposal, kelengkapan administrasi kegiatan pengabdian masyarakat. e). Penyusunan materi paparan penyuluhan hukum. f). Penyiapan ruangan penyuluhan hukum. 2). Kegiatan penyuluhan hukum meliputi: a). Pembukaan dan perkenalan dengan tokoh-tokoh masyarakat dan pengurus DKM masjid yang berada di lingkungan Kecamatan Cinere.b). Melaksanakan sosialisasi dan penyuluhan hukum mengenai hukum hibah, wasiat, wakaf, dan waris menurut Kompilasi Hukum Islam. c). Sesi diskusi dan tanya jawab interaktif dengan peserta sosialisasi dan penyuluhan. 3). Penutupan kegiatan meliputi: a). Pelaksanaan post-test untuk mengetahui tingkat keberhasilan penyuluhan. b). Sesi foto bersama dengan seluruh peserta penyuluhan dan jajaran pengurus Kecamatan Cinere. c). Kepulangan dan berpamitan dengan Camat, Lurah dan seluruh jajaran Kecamatan Cinere. d). Penyusunan laporan pelaksanaan kegiatan pengabdian kepada masyarakat.

\section{Sasaran Kegiatan}

Kegiatan pengabdian kepada masyarakat dalam bentuk sosialisasi dan penyuluhan hukum hukum hibah, wasiat, wakaf, dan waris menurut Kompilasi Hukum Islam di Kecamatan Cinere Kota Depok yang ditujukan kepada tokoh agama dan pengurus Dewan Kemakmuran Masjid (DKM). Mereka lah yang banyak bersentuhan dengan masyarakat langsung, menjadi tumpahan pertanyaan atas berbagai persoalan hukum Islam termasuk tentang hukum hibah, wasiat, wakaf, dan waris. terkait lainnya karena mereka masyarakat umum di lingkungan Kecamatan Cinere. Kegiatan penyuluhan tersebut dihadiri kurang lebih 38 orang yang terdiri dari berbagai kalangan di lingkungan Kecamatan Cinere.

\section{Hasil dan Pembahasan}

Kegiatan pengabdian kepada masyarakat dalam bentuk sosialisasi dan penyuluhan hukum tentang hukum hibah, wasiat, wakaf, dan waris menurut Kompilasi Hukum Islam secara umum telah berjalan dengan baik dan lancer sebagaimana yang diharapkan pelaksana. Staf dan personel kantor Kecamatan Cinere ikut serta membantu pelaksanaan kegiatan mulai 
sebelum kegiatan seperti penyiapan tempat, prasarana yang dibutuhkan, dan mobilisasi peserta penyuluhan sampai dengan kegiatan dilaksanakan kegiatan sosialisasi dan penyuluhan. Peserta kegiatan penyuluhan hukum terdiri dari unsur masyarakat; tokoh masyarakat, tokoh agama, dan ketua Dewan Kemakmuran Masjid (DKM) dan atau pengurus DKM lainnya. Kegiatan dilaksanakan di Aula kantor Kecamatan Cinere yang sangat refresentatif untuk penyelenggaraan kegiatan penyuluhan atau seminar sekalipun.

Kegiatan penyuluhan ini diawali dengan beberapa susunan acara yang telah ditetapkan oleh pelaksana sosialisasi dan penyuluhan hukum, yaitu sebagai berikut: 1). Pembukaan acara : pembukaan acara dilaksanakan oleh pembawa acara /MC dari unsur mahasiswa Fakultas Hukum semester 7, yaitu Saudari Ririn Daniyarti (NPM : 201610115048 dan Ika Fitri Kurniawati (NPM 201610115112), menyampaikan, susunan acara yang telah disusun beserta pengisi acaranya. .2). Sambutan-sambutan yang disampaikan oleh Fakultas Hukum Universitas Bhayangkara Jakarta Raya, yang pada kesempatan tersebut disampaikan oleh Adi Nur Rohman, S.H.I., M.Ag selaku Kaprodi IImu Hukum Fakultas Hukum Universitas Bhayangkara Jakarta Raya. Dalam kesempatan tersebut Kaprodi menyampaikan terima kasih kepada Camat Kecamatan Cinere dan seluruh jajarannya yang telah berkenan memberikan ijin dan dukungan moral serta kesediaan menggunakan tempat Aula dan prasarana lainnya kepada pihak Dosendosen Fakultas Hukum dalam rangka kegiatan sosialisasi dan penyuluhan hukum. Selain itu, Kaprodi Ilmu Hukum juga menyampaikan tentang pentingnya sosisalisasi dan penyuluhan hukum tentang hibah, wasiat, wakaf, dan waris menurut Kompilasi Hukum Islam mengingat masalah-masalah tersebut menjadi masalah hukum yang umum terjadi di tengah-tengah masyarakat. Karena itu, kehadiran tokoh agama, tokoh masyarakat, dan ketua atau pengurus DKM Masjid menjadi sangat penting pula yang menjadi penyambung informasi kepada masyarakat mengenai pengaturan hukum hibah, wasiat, wakaf, dan waris menurut Kompilasi Hukum Islam berdasarkan Instruksi Presiden Nomor 1 Tahun 1991. 3). Kegiatan ketiga, yaitu pemandu penyuluhan hukum oleh moderator yang juga dari unsur Mahasiswa Fakultas Hukum Universitas Bhayangkara Jakarta Raya, yaitu Bonaventura Harris Turino Kurniawan Sukowarjoyo (NPM : 201710115166) yang menyampaikan acara kegaitan sosialisasi dan penyuluhan hukum, tujuan kegiatan, mengenalkan para pembicara yang akan mengisi penyuluhan hukum, nama, sejarah pendidikan,dan materi yang diajarkan sebagai Dosen di Fakultas Hukum Universitas Bhayangkara Jakarta Raya. 4). Pelaksanaan Acara Sosialisasi dan Penyuluhan Hukum terdiri dari: a). Sesi pertama, penyuluh pertama, Ahmad Baihaki, S.H.I., M.H., menyampaikan materi sosialisasi tentang Kedudukan kompilasi Hukum Islam dalam sistem perundang-undangan di Indonesia dan pengaturan mengenai hukum hibah, wasiat, wakaf, dan waris menurut Kompilasi Hukum Islam. b). Sesi Kedua, penyuluh kedua, yaitu Adi Nur Rohman, S.H.I, M.Ag, menyampaikan "Urgensi Pengaturan Hukum Dan Penyelesaian Sengketa Waris, Hibah, Wasiat Dan Wakaf". c). Sesi ketiga diisi oleh pelaksana abdimas ketiga, yaitu Yulianto Syahyu, S.H., M.H. menyampaikan materi tentang pengaturan 
dan proses sertifikasi tanah wakaf di Indonesia, beberapa persoalan hukum dan cara penyelesaiannya.

Pemaparan materi sosialisasi dan penyuluhan hukum berlangsung selama kurang lebih 60 menit, dimana masing-masing pembicara menyampaikan paparan materinya selama 20 menit sesuai dengan topik yang mereka buat materi paparan. 5). Sesi diskusi dan tanya jawab interaktif. Selama berlangsungnya kegiatan sosialisasi dan penyuluhan hukum, terdapat antusiasme yang tinggi di kalangan peserta. Hal tersebut terlihat dari semangat peserta mengikuti seluruh kegiatan penyuluhan dan munculnya pertanyaan-pertanyaan yang kritis berdasarkan fakta tentang problematika hukum yang mereka temui langsung di lapangan dalam kehidupan masyarakat. Dalam sesi ini dibuka 3 (tiga) sesi pertanyaan selama kurang lebih 1 (satu) jam. 6). Sesi penutupan, yaitu Sesi ini diisi dengan kesimpulan yang disampaikan oleh pembawa acara yang dilanjutkan dengan penyerahan plakat sebagai bentuk penghargaan Fakultas Hukum Universitas Bhayangkara Jakarta Raya terhadap Camat Kecamatan Cinere dan jajarannya dalam mendukung suksesnya terselenggaranya kegiatan pengabdian masyarakat tersebut. Kemudian acara ditutup dengan pembacaan doa yang dilanjutkan dengan melakukan sesi foto bersama antara tim pengabdi, jajaran perangkat Kecamatan Cinere beserta seluruh peserta sosialisasi dan penyuluhan hukum.

Guna mengetahui tingkat keberhasilan kegiatan penyuluhan ini terhadap pemahaman masyarakat, mereka diminta untuk mengisi lembar pertanyaan post-test berkaitan dengan materi penyuluhan yang disampaikan. Dari penyebaran kuesioner tersebut, didapatkan hasil peningkatan pengetahuan yang cukup signifikan sebagai berikut:

Tabel 2. Hasil Pre-test dan Post-tes

\begin{tabular}{|c|c|c|c|c|c|}
\hline \multirow{3}{*}{ No } & \multirow{3}{*}{ Pertanyaan } & \multicolumn{4}{|c|}{ Hasil Test } \\
\hline & & \multicolumn{2}{|c|}{ Pre-test } & \multicolumn{2}{|c|}{ Post-test } \\
\hline & & Jumlah & (\%) & Jumlah & $(\%)$ \\
\hline 1 & $\begin{array}{l}\text { Memahami tentang konsep wakaf, } \\
\text { hibah, wasiat dan waris }\end{array}$ & 18 & 47.37 & 20 & 52.63 \\
\hline 2 & $\begin{array}{l}\text { Mengetahui regulasi wakaf, hibah, } \\
\text { wasiat dan waris di Indonesia }\end{array}$ & 7 & 18.42 & 31 & 81.58 \\
\hline 3 & $\begin{array}{l}\text { Mengetahui bentuk-bentuk } \\
\text { pelanggaran peraturan wakaf, hibah, } \\
\text { wasiat dan waris di Indonesia }\end{array}$ & 8 & 21.05 & 30 & 78.95 \\
\hline 4 & $\begin{array}{l}\text { Memahami urgensi sertifikasi tanah } \\
\text { wakaf di Indonesia }\end{array}$ & 12 & 31.58 & 26 & 68.42 \\
\hline 5 & $\begin{array}{l}\text { Mengetahui tata cara pendaftaran } \\
\text { tanah wakaf }\end{array}$ & 8 & 21.05 & 30 & 78.95 \\
\hline
\end{tabular}

sumber: Hasil Penelitian (2020)

Dari hasil Tabel 2, terlihat bahwa peningkatan pengetahuan dan pemahaman masyarakat cukup signifikan. Hal ini mengindikasikan bahwa sebelum dilakukan penyuluhan hukum, sebagian besar mereka belum mengetahui secara mendalam terkait hukum perwakafan di Indonesia. Adapun setelah dilaksanakannya penyuluhan ini, sebagian besar masyarakat 
lebih mengerti dan memahami hukum perwakafan di Indonesia serta meningkatnya kesadaran hukum akan urgensi sertifikasi tanah wakaf serta tata cara pendaftarannya. Lebih jelasnya, peningkatan pemahaman masyarakat digambarkan dalam diagram berikut:

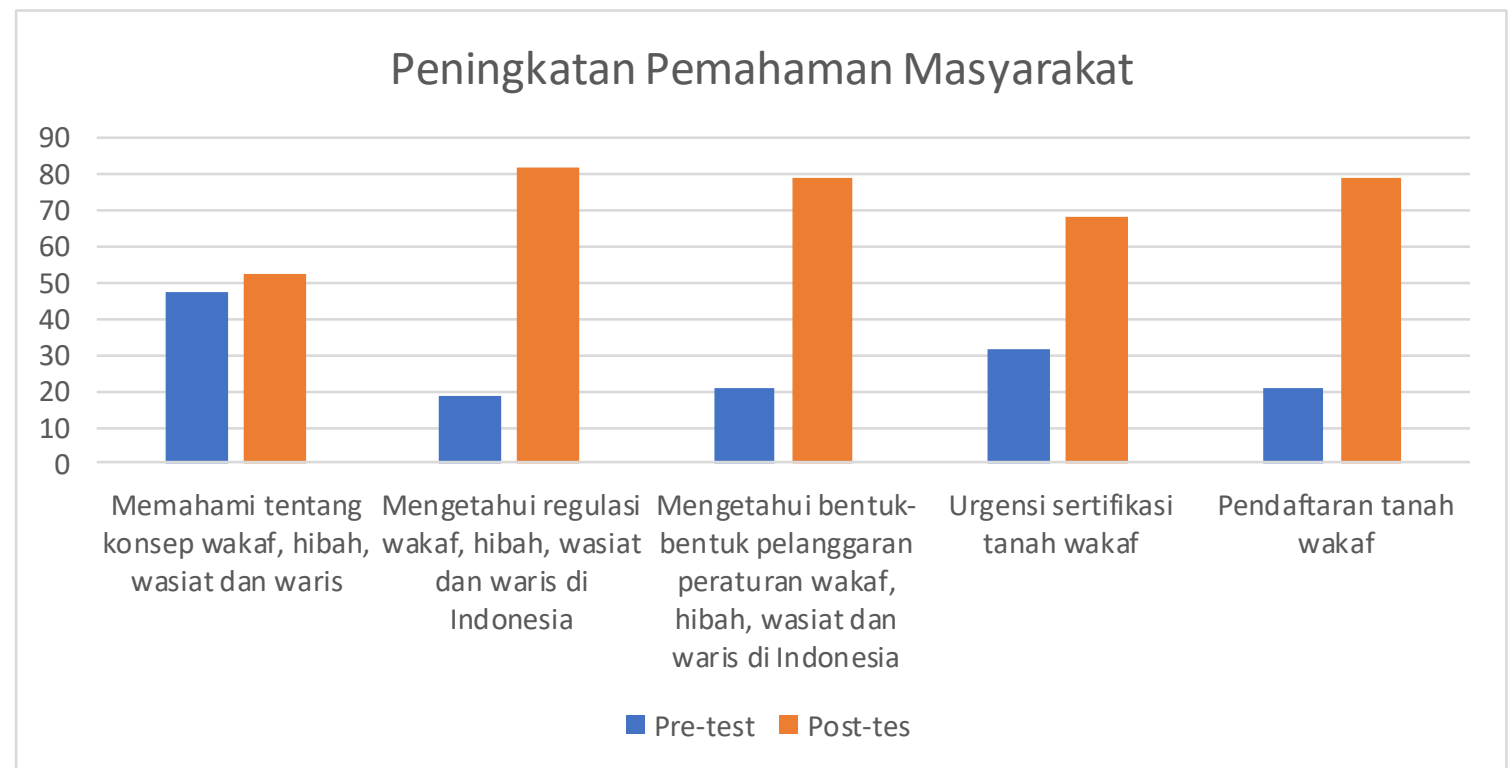

Sumber: Hasil Pengolahan Data (2020)

Gambar 1. Diagram Peningkatan Pemahaman Masyarakat

Kegiatan pengabdian kepada masyarakat ini juga melibatkan mahasiswa Fakultas Hukum Universitas Bhayangkara Jakarta Raya. Hal ini dimaksudkan agar para mahasiswa dapat ambil bagian dan terlibat langsung dalam hal mensosialisasikan peraturan-peraturan yang berlaku. Di samping itu, pengalaman dan pengamalan ilmu dapat secara langsung mereka terapkan sehingga kemajuan dalam bidang akademik akan jauh lebih terasa dimana para mahasiswa akan ikut mendalami materi-materi yang akan disampaikan.

\section{Kesimpulan}

Berdasarkan paparan diatas dapat disimpulkan beberapa hal sebagai berikut: 1). Kegiatan pengabdian kepada masyarakat dalam bentuk sosialisasi dan penyuluhan hukum tentang hibah, wasiat, wakaf, dan waris di Kecamatan Cinere telah terlaksana dengan baik dan lancar. 2). Kegiatan pengabdian kepada masyarakat dalam bentuk sosialisasi dan penyuluhan hukum mendapat respon yang sangat positif dari para peserta. Hal ini tergambar dari antusiasme peserta mengikuti acara sosialisasi dan penyuluhan sampai tuntas. Selian itu, ditandai pula dengan munculnya banyak pertanyaan-pertanyaan yang terkait dengan topik masalah hukum yang disampaikan. Hal itu karena topik yang dibahas berkaitan langsung dengan masalah-masalah hukum yang sering mereka hadapi di dalam masyarakat. 3). Munculnya kesadaran hukum tentang adanya Kompilasi Hukum Islam, yang mengatur tentang hibah, wasiat, wakaf, dan waris yang saat ini menjadi salah satu landasan hukum bagi masyarakat. pemahaman masyarakat peserta penyuluhan tentang hukum perwakafan dan tata 
cara pendaftaran tanah wakaf di Indonesia dan juga meningkatnya kesadaran hukum mereka akan sertifikasi tanah wakaf dalam menjamin kepastian hukum objek wakaf. Kegiatan pengabdian kepada masyarakat bagi perguruan tinggi diharapkan tidak hanya menjadi kegiatan insidentil sebagai pemenuhan semata pelaksanaan tugas tridharma seorang dosen, tetapi juga menjadi jalinan kerjasama yang berkesinambungan dalam bentuk konsultasi, pelatihan, pendampingan hukum atas berbagai persoalan hukum yang muncul di tengah masyarakat.

\section{Ucapan Terima Kasih}

Kami ucapkan terimakasih kepada seluruh pimpinan dan staf Kantor Kecamatan Cinere serta mahasiswa Fakultas Hukum Universitas Bhayangkara Jakarta Raya yang telah membantu kami sehingga kegiatan ini bisa berjalan lancar.

\section{Daftar Pustaka}

Saenani, A, Beni, \& Falah, S. (2011). Hukum Perdata Islam di Indonesia, Bandung: Pustaka Setia.

Ali, M.D, (1996). Hukum Islam Pengantar IImu Hukum dan Tata Hukum Islam di Indonesia, Jakarta: Rajawali Press.

Hartini, \& Harahab, Y. (2000). Pengaruh Kompilasi Hukum Islam dalam Penyeleswaian Perkara Kewarisan pada Pengadilan Agama, Mimbar Hukum Nomor 35, V,

Manan, A. (1998). Beberapa Masalah Hukum tentang Wasiat dan Permasalahannya dalam Konteks Kewenangan Pengadilan Agama, dalam Mimbar Hukum Aktualisasi Hukum Islam Nomor 38 Tahun IX,

Mulyadi. (2008). Hukum Waris Tanpa Wasiat, Semarang: Badan Penerbit Universitas Diponegoro Semarang,

Ramulyo, I. (2004). Perbandingan Hukum Kewarisan Islam dengan Kewarisan Kitab UU Hukum Perdata, Jakarta: Sinar Grafika,

Rasyid, Roihan A, (1999). Pengganti Ahli Waris dan Wasiat Wajibah dalam Cik Hasan Bisri et. Al (eds) Kompilasi Hukum Islam dan Peradilan Agama dalam Sistem Hukum Nasional, Jakarta: Logos Wacana IImu,

Rofiq, A. (2015). Hukum Perdata Islam di Indonesia, Jakarta: Rajawali Press,

Sabiq, Sayid, Fiqh Al Sunnah, juz 3, Kairo: Maktabah Dar al Turast, tt

Thalib, Sajuti. (1981). Hukum Kewarisan Islam di Indonesia, PT. Bina Aksara,

Zuhaily, Wahab, Fiqh Al Islam Wa Adillatuhu, Beirut: Dar al Fikr, tt

Undang-Undang Nomor 1 Tahun 1974 tentang Perkawinan

Undang-Undang Nomor 7 Tahun 1989 tentang Peradilan Agama

Undang-Undang Nomor 3 Tahun 2006 tentang perubahan atas Undang-Undang Nomor 7 Tahun 1989

Undang-Undang Nomor 50 Tahun 2009 tentang Perubahan Kedua Atas Undang-Undang 
Nomor 7 Tahun 1989

Instruksi Presiden Nomor 1 Tahun 1991 tentang Kompilasi Hukum Islam

Ibnu Rusyd, Bidayatul Mujtahid, Juz 2, Semarang: Usaha Keluarga, tt

Ibnu Katsir, Tafsir al-Quran al-Karim, Kairo: Dar Ihya Al Kutub Al 'Arabiyah, tt 